\title{
A cross-sectional study of olfactory and taste disorders among COVID-19 patients in China
}

Jian-Hui Li $\mathrm{i}^{1,2,3,4+}$, Yi Sun ${ }^{5+}$, Mei-Rong Li ${ }^{6,7,8+}{ }^{\prime}$, Hu Yuan ${ }^{1,2+}$, Chang-Liang Yang ${ }^{5}$, Cheng-Cheng Huang ${ }^{5}$, Feng-Jie Zhou ${ }^{5}$, Rui-Yao Chen ${ }^{5}$, Lei-Bo Zhang ${ }^{5}$, Ning Yu ${ }^{1,2}$, Qiong Liu ${ }^{1,2}$, Jing-Jing He ${ }^{1,2}$, Xue-Jun Zhou ${ }^{1,2}$, Xiao-Bing Fu ${ }^{6,7,8^{*}}$ and Shi-Ming Yang ${ }^{1,2^{*}}$

\begin{abstract}
To determine the prevalence and clinical features of olfactory and taste disorders among coronavirus disease 2019 (COVID-19) patients in China. A cross-sectional study was performed in Wuhan from April 3, 2020 to April 15, 2020. A total of 187 patients with confirmed severe acute respiratory syndrome coronavirus 2 (SARS-CoV-2) completed face-to-face interviews or telephone follow-ups. We found that the prevalence of olfactory and taste disorders was significantly lower in the Chinese cohort than in foreign COVID-19 cohorts. Females were more prone to olfactory and taste disorders. In some patients, olfactory and taste disorders precede other symptoms and can be used as early screening and warning signs.
\end{abstract}

Keywords: COVID-19, SARS-CoV-2, Olfactory, Taste

\section{Dear Editor,}

The spread of coronavirus disease 2019 (COVID-19) infection abroad has highlighted a novel and atypical set of symptoms: olfactory and taste disorders. It was not reported by most of the early studies from China and is still neglected in Chinese COVID-19 patients. Herein, we present the prevalence and clinical features of olfactory and taste disorders among COVID-19 patients in China.

A cross-sectional study was performed in Wuhan from April 3, 2020 to April 15, 2020. A total of 187 patients with confirmed severe acute respiratory syndrome coronavirus 2 (SARS-CoV-2) infection were admitted to the General Hospital of Central Theater Command of PLA in Wuhan, and face-to-face interviews or telephone

\footnotetext{
*Correspondence: fuxiaobing@vip.sina.com; yangsm301@263.net ${ }^{\dagger} J$ Jian-Hui Li, Yi Sun, Mei-Rong Li and Hu Yuan contributed equally to this work

${ }^{1}$ College of Otolaryngology Head and Neck Surgery, Chinese PLA General Hospital, Beijing 100853, China

${ }^{6}$ Research Center for Tissue Repair and Regeneration Affiliated to the Medical Innovation Research Division and 4th Medical Center, PLA General Hospital and PLA Medical College, Beijing 100853, China Full list of author information is available at the end of the article
}

follow-ups were completed. The demographic characteristics of olfactory and taste disorders are shown in Additional file 1: Table S1. The exclusion criteria were patients who were unable to independently complete the questionnaire, patients who had previous olfactory or taste disorders, and patients who were currently in the intensive care unit (ICU). A visual analog scale was used to score the patients' olfactory status and taste. These data were also collected through online forms of discharged patients. SPSS version 22.0 was used to perform the statistical analysis.

The data analyses have led us to draw the following conclusions. Compared with the foreign cohort, the prevalence of smell and taste disorders in the Chinese cohort was significantly lower (Additional file 1 : Table S1). The prevalence of olfactory and taste disorders in COVID-19 patients was higher in females than in males (Additional file 1: Table S1). In some patients, olfactory and taste disorders precede other symptoms and can be used as early screening and warning signs (Additional file 1: Table S2). The recovery of olfactory and taste function was independent of age; females have original author(s) and the source, provide a link to the Creative Commons licence, and indicate if changes were made. The images or other third party material in this article are included in the article's Creative Commons licence, unless indicated otherwise in a credit line to the material. If material is not included in the article's Creative Commons licence and your intended use is not permitted by statutory regulation or exceeds the permitted use, you will need to obtain permission directly from the copyright holder. To view a copy of this licence, visit http://creativecommons.org/licenses/by/4.0/. The Creative Commons Public Domain Dedication waiver (http://creativeco mmons.org/publicdomain/zero/1.0/) applies to the data made available in this article, unless otherwise stated in a credit line to the data. 
an easier recovery than males; olfactory or taste disorders were not easy to recover for those who are clinically classified as severe; when the olfactory or taste disorder itself was severe, it was not easy to recover; and olfactory or taste disorders that occurred in the early stage of the disease were more likely to recover than late-stage symptoms (Additional file 1: Table S3).

According to our research results, the incidence of olfactory and taste disorders in Chinese patients is markedly lower than that reported abroad, which is $64.4 \%$ [1]. The possible reason may be that the expression of the angiotensin-converting enzyme 2 (ACE2) receptor is different in the nasopharynx between East Asians and Europeans [2]. Increased expression of ACE2 in the nasopharynx may lead to an increased risk of olfactory and taste symptoms. The other possible reason is that the virus has mutated during the transmission process, or there are different strains. Different subtypes of viruses have different affinities and neurotoxicity to mucosal receptors in the olfactory and gustatory regions, resulting in differences in their biological behavior [3].

Olfactory disorders were significantly more prevalent among females than among males. The ACE2 gene is located on the $\mathrm{X}$ chromosome, so female individuals should have a higher ACE2 level [4], which might be the reason why they are more likely to be infected with SARS-CoV-2 than males. In addition, due to the effect of estrogen, women's sense is more sensitive than men's, and women's sense of smell fluctuations more obviously than men's.

The pathophysiology of SARS-CoV-2's influence on the olfactory and taste systems is unclear. Nevertheless, neuroinvasion through the olfactory sensory neurons (OSN) appears to be dominant because these cells are clearly the most susceptible to infection in the nasal cavity, and the olfactory bulb is the first central nervous system (CNS) tissue colonized upon intranasal inoculation [5]. Olfactory or taste disorders in the early stage of disease may trigger a series of early warning mechanisms to quickly mobilize the body's immune system to fight the virus's attack, thereby preventing the virus from further attacking other important tissues and organs. Olfactory or taste disorders in the early stage of the disease may also mean that the host's immune response is strong and effective, which is more conducive to the recovery of function.

Generally, there is no fever, cough or other symptoms in the early stage. These may lead to delays in diagnosis, treatment and further spread of the infections. We would consider olfactory or taste dysfunction as a possible early-warning symptom, especially in the absence of rhinitis. Compared with nucleic acid detection and chest CT, olfactory or taste disorder is a unique screening index because of its simplicity and low cost. Early identification of suspected patients, isolation monitoring, early diagnosis and treatment of COVID19 patients are of great significance for China and other affected countries to conduct more accurate prevention and more efficient monitoring of COVID-19.

\section{Abbreviations}

ACE2: Angiotensin-converting enzyme 2; CNS: Central nervous system; COVID19: Coronavirus disease 2019; ICU: Intensive care unit; OSN: Olfactory sensory neurons; SARS-CoV-2: Severe acute respiratory syndrome coronavirus 2.

\section{Supplementary Information}

The online version contains supplementary material available at https://doi. org/10.1186/s40779-021-00339-y.

Additional file 1. Table S1. Demographic characteristics of olfactory and taste disfunction in 187 COVID-19 patients. Table S2. Occurrence time and the corresponding proportion of personnel about olfactory and taste disorders. Table S3. Functional recovery vs. non-recovery in COVID-19 patients with olfactory or taste impairments.

\section{Acknowledgements}

I would like to thank academician Fu-Sheng Wang for his coordination and support during the research. Thanks to professor En-Qiang Qin for providing the background information and professional information related to the epidemic

\section{Authors' contributions}

All authors contributed to the study conception and design. SMY, XBF and CLY supervised the overall study. YS, CCH, FJZ, RYC, LBZ collected clinical data. $J H L$ and MRL made the table. HY, QL, JJH and XJZ searched the literature. JHL and MRL wrote the manuscript. HY and NY revised the manuscript. All authors read and approved the final manuscript.

\section{Funding}

This study was supported in part by the National Natural Science Foundation of China (81830064, 81721092, 81971841), the National Key Research and Development Plan (2017YFC1103304, 2017YFC1104701).

\section{Availability of data and materials}

The datasets generated and analyzed during the current study are not publicly available due to individual privacy, but are available from the corresponding author on reasonable request.

\section{Declarations}

Ethics approval and consent to participate

This research study was conducted retrospectively from data obtained for clinical purposes. The Medical Ethics Committee of PLA General Hospital has confirmed that no ethical approval is required.

Consent for publication

Not applicable.

Competing interests

The authors declare that they have no competing interests. 


\section{Author details}

${ }^{1}$ College of Otolaryngology Head and Neck Surgery, Chinese PLA General Hospital, Beijing 100853, China. ${ }^{2}$ National Clinical Research Center for Otolaryngologic Diseases, No. 28 Fuxing Road, Beijing 100853, China. ${ }^{3}$ Department of Otolaryngology Head and Neck Surgery, Chinese PLA General Hospital Hainan Hospital, Sanya 572013, China. ${ }^{4}$ Hainan Clinical Research Center for Otolaryngologic Diseases, Sanya 572013, China. ${ }^{5}$ Department of Otolaryngology Head and Neck Surgery, General Hospital of Central Theater Command of PLA, Wuhan 430070, China. ${ }^{6}$ Research Center for Tissue Repair and Regeneration Affiliated to the Medical Innovation Research Division and 4th Medical Center, PLA General Hospital and PLA Medical College, Beijing 100853, China. ${ }^{7}$ PLA Key Laboratory of Tissue Repair and Regenerative Medicine and Beijing Key Research Laboratory of Skin Injury, Repair and Regeneration, No. 28 Fuxing Road, Beijing 100853, China. ${ }^{8}$ Research Unit of Trauma Care, Tissue Repair and Regeneration, Chinese Academy of Medical Sciences, Beijing 100853, China.

Received: 20 July 2020 Accepted: 3 Auqust 2021

Published online: 13 September 2021

\section{References}

1. Spinato G, Fabbris C, Polesel J, Cazzador D, Brosetto D, Hopkins C, et al. Alterations in smell or taste in mildly symptomatic outpatients with SARS-CoV-2 infection. JAMA. 2020;323(20):2089-90.

2. Cao Y, Li L, Feng Z, Wan SQ, Huang PD, Sun XH, et al. Comparative genetic analysis of the novel coronavirus (2019-nCoV/SARS-CoV-2) receptor ACE2 in different populations. Cell Discov. 2020;6:11.

3. Chan JF, Yuan SF, Kok KH, To KK, Chu H, Yang J, et al. A familial cluster of pneumonia associated with the 2019 novel coronavirus indicating person-to-person transmission: a study of a family cluster. Lancet. 2020;395(10223):514-23.

4. Bhatia K, Zimmerman MA, Sullivan JC. Sex differences in angiotensinenzyme modulation of Ang (1-7) levels in normotensive WKY rats. Am J Hypertens. 2013;26(5):591-8.

5. Dube M, Le Coupanec A, Wong AHM, Rini JM, Desforges M, Talbot PJ. Axonal transport enables neuron-to-neuron propagation of human coronavirus OC43. J Virol. 2018;92(17):e00404-e418.
Ready to submit your research? Choose BMC and benefit from:

- fast, convenient online submission

- thorough peer review by experienced researchers in your field

- rapid publication on acceptance

- support for research data, including large and complex data types

- gold Open Access which fosters wider collaboration and increased citations

- maximum visibility for your research: over $100 \mathrm{M}$ website views per year

At BMC, research is always in progress.

Learn more biomedcentral.com/submissions 